\title{
El fenómeno de las puertas giratorias
}

\author{
Fernando González Barroso \\ Transparencia Internacional España \\ fernando.gonzalez@,transparencia.org.es
}

DOI: http://dx.doi.org/10.20318/eunomia.2016.3296

Una mala regulación y un peor desempeño

El fenómeno de las "puertas giratorias" como bien ha señalado Elisa de la Nuez, se caracteriza por un movimiento de entrada y salida del sector privado al público y del público al privado, de personas que han ocupado altas responsabilidades en las instituciones del estado. Principalmente acotados, en nuestro país, a cargos que han ejercicio responsabilidades políticas en sectores de actividad económica; tales como la energía, la banca, la construcción, la sanidad, o la defensa. Un sector este último, que aparece poco en la prensa vinculada a estos casos de puertas giratorias pero que a mi juicio es paradigmático del fenómeno, en la persona del actual Ministro de Defensa, Pedro Morenés. Una persona que en las últimas décadas ha ocupado importantes puestos de responsabilidad en los gobiernos de Aznar, como Secretario de Estado de Defensa, y después Secretario de Estado de Seguridad, para finalmente ocupar la máxima responsabilidad ministerial con Rajoy. En el interregno ha ocupado importantes cargos en los consejos de administración de los complejos empresariales del lobby de la defensa. Es conocida y está acreditada su vinculación con MBDA complejo empresarial dedicado a la fabricación de misiles, por poner un ejemplo.

Es cierto que este fenómeno de las "puertas giratorias" no es nuevo en nuestro país, baste recordar que ya el ex presidente Calvo Sotelo ocupó un cargo en el consejo de administración de la antigua FENOSA, o Felipe González miembro del consejo de administración de Gas Natural, y más reciente el ex vice-presidente Rodrigo Rato en Bankia.

Por tanto el fenómeno ni es nuevo, ni privativo de nuestro país, nuestros vecinos están afectados por este mismo problema. Prueba de ello es que un estudio realizado por la OCDE en 2009 sobre el fenómeno del "revolving door" demostró que el $75 \%$ de los altos cargos en Reino Unido provenían de la empresa privada; es decir que aprovechaban su paso por el sector público para hacer contactos y conocer el funcionamiento de las administraciones y volvían a sus empresas para seguir vigilando sus intereses. En Francia, ocurre algo parecido, y lo ha llevado al Código Penal, que establece en su art. 432-13 tres años de prisión y una multa de 200.000 euros para aquellos altos responsables públicos que desempeñen actividades privadas vinculadas a su ámbito de decisión política, hasta tal punto que 
el Presidente Hollande hizo firmar a todos los miembros de su gabinete un código ético, o deontológico, por el que se comprometían a observar la máxima integridad y honradez en el ejercicio de las responsabilidades públicas; todo ello, para evitar el fenómeno del "pantouflage" y el conflicto de intereses.

En nuestro país lo nuevo es que este fenómeno de las puertas giratorias ha tomado una relevancia especial en el contexto de crisis económica, que ha metamorfoseado en crisis política e institucional, en el que ese "no nos representan" que enarboló el $15 \mathrm{M}$ simbolizaba un divorcio lento que se ha venido produciendo en nuestro país entre las élites políticas y económicas, y el resto de la ciudadanía, que en los momentos más duros de la crisis observaban atónitos como familias humildes incluso mayores, eran desahuciados de sus hogares sin mayor compasión ni respuesta desde las instancias política, sin poder apelar a ningún tipo de justicia en defensa de estas situaciones, mientras los más altos representantes de las instancias políticas encontraban cobijo y suelos suculentos por pertenecer a consejos de administración de grandes empresas que le pagaban por acceder a su agenda de contactos, o bien, devolviendo favores prestados.

Por cierto, no debemos olvidar que este no es un fenómeno exclusivo de la Administración General de Estado, en las Comunidades Autónomas, y en los gobiernos locales, nos encontramos con el mismo problema. Conocido es el caso del ex consejero de Sanidad de la Comunidad de Madrid Juan José Güemes que tras dejar su cargo, pasó a ocupar un puesto relevante en el consejo de administración de Unilabs.

Como refiere Elisa, en España tenemos regulado el conflicto de intereses recientemente la Ley 3/2015 de 30 de marzo, regula el ejercicio de los altos cargos de la Administración General de Estado, de su articulado, cabría resaltar por ejemplo, la creación de la Oficina de Conflicto de Intereses, ubicada en el Ministerio de Economía y Administraciones públicas, órgano encargado de vigilar y controlar el ejercicio profesional y la actividad de los responsables públicos, y de aquellos que proceden del sector privado y pasar a ocupar cargos públicos. Es de señalar, que son dos años el tiempo que debe pasar desde que un cargo público pasa a la actividad privada, no pudiendo ocupar cargo en ninguna empresa perteneciente a un sector sujeto a regulación estatal. Sin embargo, el régimen de sanciones parece insuficiente. La ley trata de frenar el problema, pero deja resquicios suficientes como para que su incumplimiento, en caso de falta grave, tampoco lleve aparejada una sanción realmente importante para el afectado.

Es verdad, que es una materia compleja de regular, de forma que sea posible que el sector público se nutra de personas con competencias, conocimientos y experiencia en sectores complejos, y que su vuelta a la actividad no sea muy lesiva para el afectado de modo que el sector público no tenga capacidad ni atractivo para estos talentos. Pero no es menos cierto, que en un modelo de estado como el nuestro, clientelar y en el que priman las relaciones de confianza y lealtad política sobre los conocimientos y experiencia técnica, el sector público tiene muy limitada esta capacidad. La pregunta sería: ¿cómo permitir una fluidez en estos traspasos entre lo público y lo privado preservando la integridad y honestidad en el ejercicio de cargo público? Probablemente, una vez más, la ley tenga un alcance limitado, pero no despreciable, tener que hablar de cómo favorecer comportamientos éticos y honestos; también en el ejercicio de la actividad privada, porque no olvidemos que las grandes empresas; estas grandes empresas que fichan a los altos cargos, son también las que están en el punto de mira de los grandes casos de corrupción vinculados a la contratación pública; el principal nicho de la corrupción en nuestro país. En este punto, y sin ánimo ni mucho menos de 
agotar el debate, se me ocurre, tomando el testigo de lo expresado por Elisa en sus últimas reflexiones, quizás la solución sea la resultante de un conjunto de medidas, entre las que no descartaría el Código Penal, como nuestros amigos franceses, pero también habría que seguir trabajando un aspecto fundamental, cual es el de la profesionalización de la Función Pública Directiva en nuestro país. El Estatuto Básico del Funcionario Público de 2007, ya fue un comienzo para desbrozar este terreno, que parece haber quedado en dique seco consecuencia de las medidas destinadas a la racionalización de las administraciones públicas y su adelgazamiento, en el contexto de crisis y ajuste de los últimos años, pero que más temprano que tarde habrá que retomar porque será una, no la única, pero si una de las palancas de cambio que encauce este problema a niveles más razonables, y limitados. Asimismo, servirá para avanzar en la modernización y necesaria profesionalización de las administraciones, su despolitización. A través de procesos selectivos meritocráticos y de formación en competencias y capacidades de dirección y liderazgo, con una componente fundamental en los aspectos éticos y de integridad en el ejercicio público. De esta forma además se aclarará y sentarían las bases para una relación entre la alta dirección pública, y el nivel político, en base competencia y méritos profesionales, y no lealtades personales o de partido, que ha sido y continúa siendo la tónica general en nuestras administraciones, politizadas hasta unos niveles absolutamente insoportables para la necesaria higiene y legitimidad política e institucional de nuestro sistema político, por no hablar de las importantes distorsiones que ello produce como consecuencia de la ineficacia de unas organizaciones públicas mal dirigidas, y políticas públicas capturadas por los grupos de interés.

Es verdad, se puede objetar, que esta no será la solución definitiva, ni mucho menos, de hecho en Reino Unido donde el nivel de profesionalización de la función pública llega hasta los niveles más altos, continúan padeciendo un importante problema de "revolving door", además de otros problemas consecuencia de la profesionalización al más alto nivel. Les invito a visualizar la serie de los 80's "Yes Minister" en uno de los capítulos en tono jocoso se ve cómo un ministro llega a su despacho y depende absolutamente de sus subordinados profesionales para todo, sin haberlos podido elegir, sin ser de su confianza, ni conocer la organización ni sus lógicas, ni haberse sometido a ninguna elección democrática. Sin embargo; este, ahora en nuestro país no es el problema, sino el contrario. Por tanto, esta medida, junto con otras, además de la contundente repulsa y condena social, deben limitar estos comportamientos, hasta niveles mínimos. Mientras tanto, educar a nuestras nuevas generaciones en el aprecio y valoración de lo público, y del interés general, es fundamental como medida preventiva. 